\title{
Knowledge and practice regarding hypertension and diabetes among the elderly in a rural area in southern India following an educational program: A comparative study
}

\author{
Arvind Kasthuri, Aditi Krishnamurthy, Pretesh Rohan Kiran, As Mohammad, Deepthi Shanbhag \\ Department of Community Health, St John's Medical College, Bangalore, Karnataka, India
}

\section{A B S T R A C T}

Aim: Hypertension and diabetes mellitus are important problems in the elderly. They can largely be avoided through appropriate lifestyle modification.We implemented an ongoing education program for the elderly in the villages near Bangalore, Southern Karnataka, India. This study aimed to assess the knowledge and practice regarding hypertension and diabetes among elderly residents in the study area with and without exposure to the education program. Materials and Methods: Elderly residents of three villages who attended the educational sessions ("exposed") and two similar villages without educational exposure ("unexposed") were identified, matched with regard to age and gender, and interviewed to assess the knowledge and practice regarding hypertension and diabetes. The responses were scored, and mean scores were calculated in the two groups. Results and Discussion: A total of I 30 elderly persons, 65 "exposed" and 65 "unexposed" to the education program were interviewed. Overall, the "exposed" group scored significantly higher than the "unexposed" group with respect to knowledge (II.I7 vs $4.97, P<0.05)$ and practice $(I .35$ vs $0.40, P<0.05)$ regarding hypertension. Knowledge (I4.85 vs 6.57 , $P<0.05)$ and practice ( 1.49 vs $0.34, P<0.05)$ scores regarding diabetes were also higher in the "exposed" group. However, the scores were less than $50 \%$ of the maximum attainable score even in the "exposed" group showing the need for further educational input. Conclusion: Regular health education sessions by physicians, nurses, and community health workers for the elderly are a useful strategy in improving the knowledge and practice for preventing and managing chronic disease. This is a model of health promotion in the elderly.

Key words: Diabetes, elderly, hypertension, knowledge, practice

\section{INTRODUCTION}

Chronic diseases are a leading cause of morbidity and mortality globally. In India, chronic disease is estimated to account for $53 \%$ of all deaths and $44 \%$ of disabilityadjusted life-years (DALYs) lost in 2005. ${ }^{[1,2]}$ India has the largest number of diabetics in the world with a prevalence

\begin{tabular}{|l|l|}
\hline \multicolumn{2}{|c|}{ Access this article online } \\
\hline Quick Response Code: & Website: \\
\hline & www.josh.net \\
\hline & \\
\hline
\end{tabular}

of $3.8 \%$ in rural adults and $11.8 \%$ in urban adults. ${ }^{[3,4]}$ Epidemiological studies show that the prevalence of hypertension in adults is $25 \%$ in urban areas and $10 \%$ in rural areas in India. ${ }^{[5]}$ The prevalence of these diseases rises with age. The proportion of persons above the age of

This is an open access article distributed under the terms of the Creative Commons Attribution-NonCommercial-ShareAlike 3.0 License, which allows others to remix, tweak, and build upon the work non-commercially, as long as the author is credited and the new creations are licensed under the identical terms.

For reprints contact: reprints@medknow.com

How to cite this article: Kasthuri A, Krishnamurthy A, Kiran PR, Mohammad A, Shanbhag D. Knowledge and practice regarding hypertension and diabetes among the elderly in a rural area in southern India following an educational program: A comparative study. J Soc Health Diabetes 2016;4:30-5.

Corresponding Author: Dr. Pretesh Rohan Kiran, Department of Community Health, St John's Medical College, Bangalore - 560034 , Karnataka, India. E-mail: preteshkiran@gmail.com 
60 years in India is $8 \%{ }^{[6]}$ and this proportion is expected to rise to $21.3 \%$ by $2050 .{ }^{[7]}$ Elderly subjects in rural areas are especially less likely to be aware of and be on treatment for chronic diseases such as hypertension. ${ }^{[8]}$ It is a difficult task to address these problems with limited health resources.

Studies suggest that $80 \%$ of heart disease, stroke, type 2 diabetes, and $40 \%$ cancers could be avoided through a healthy diet, regular physical activity, and the avoidance of tobacco use. ${ }^{[9]}$ The Department of Community Health, St. John's Medical College, has a Senior Citizen Health Service (SCHS) since the year 2005. As part of this service, monthly geriatric clinics are held in village outreach sites. Preceding each clinic is a short group education session on chronic disease prevention, with a focus on hypertension and diabetes mellitus, using methods such as roleplays and stories, along with simple flip charts developed for the purpose. The educational content is based on the World Health Organization (WHO) Guidelines for the Prevention of Cardiovascular Disease. ${ }^{[10]}$ The educational input is reinforced at individual consultations by doctors and by a health worker who makes home visits between clinics.

This study was undertaken to assess and document the effect of this education program, and was aimed at assessing the knowledge and practice regarding hypertension and diabetes among elderly residents of a rural area in Karnataka, India with and without exposure to the education program.

\section{MAterials And Methods}

This study was conducted in five geographically contiguous villages in the Bangalore district, Karnataka, India in November 2009. These villages belonged to two groups: One group of three villages where the elderly (defined as those $\geq 60$ years) were "exposed" to the education program and another group of two similar villages where the elderly were "unexposed," since the education program was not carried out in these villages. An interview schedule assessing the baseline demographics, socioeconomic status, reported disease status, and questions relating to knowledge and practice regarding hypertension and diabetes mellitus was developed, validated by circulation to experts and peers, and pretested. The knowledge and practice regarding hypertension and diabetes mellitus were divided into key components. Each key component had subcomponent answers. A score of 1 was given for a correct answer and 0 for an incorrect answer. Total scores under each key component and overall scores were calculated, representing the "score" obtained by each individual respondent. The key components, subcomponents, and scoring in the questionnaire are outlined in Table 1.

Assuming that the difference in mean knowledge scores obtained by the two groups is 5 marks, with an expected standard deviation (SD) of 10 , the number of subjects required in each group is 63 , with $95 \%$ confidence and $80 \%$ power. Elderly persons residing in the "exposed" group of villages who attended at least six education sessions in the preceding 2 years were listed, stratified for gender, and the required number was selected by stratified random sampling. Elderly residents of the "unexposed" villages were enumerated, and the same number was selected using stratified random sampling to ensure that the gender and age distribution were similar to the "exposed" group. Following translation, a set of locally resident community health workers were trained on the use of the schedule, and were deployed to collect information from the study subjects. The workers were supervised by a doctor-member of the team, and data were collected following the obtaining of consent at community and individual levels. Elderly persons who were not available after three visits to their house, who were moribund, or otherwise unable to participate in the interview (communication difficulties like hearing and speech impairment) were excluded and replaced with others selected randomly from the list of elderly. Data were entered into Microsoft (MS) Excel spreadsheets and was analyzed using Epi Info 6.0.

\section{RESULTS}

\section{Baseline characteristics of the study population}

A total of 130 elderly persons were interviewed, 65 residents "exposed" to the education program and 65 "unexposed" to the education program. Forty females and 25 males were interviewed in each group. There was no significant difference in the mean age, education, or economic status of the subjects in the "exposed" and "unexposed" groups. Self-reported hypertension and diabetes were significantly higher in the "exposed" group [Table 2].

Knowledge regarding hypertension and diabetes mellitus Table 3 shows the mean knowledge scores for hypertension and diabetes mellitus obtained by the groups "exposed" and "unexposed" to the education program as a whole and among those who reported having either of the two diseases.

The maximum attainable score was 34 for hypertension and 41 for diabetes mellitus. Overall, the "exposed" group scored significantly higher than the "unexposed" with respect to knowledge regarding both the diseases. The 


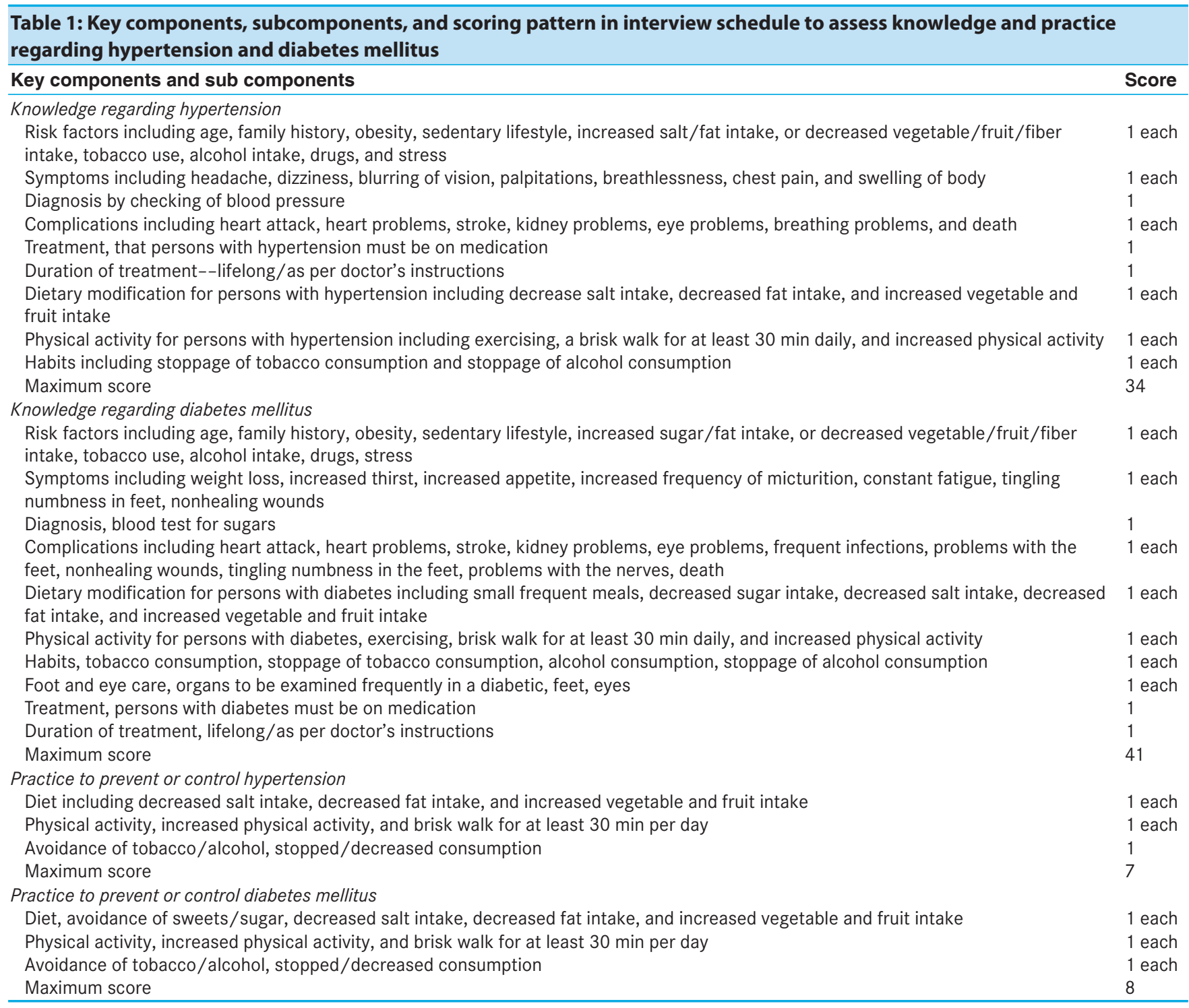

scores are significantly higher in the "exposed" group compared with the "unexposed" group even among reported hypertensives and diabetics.

\section{Practice of lifestyle modification for hypertension} and diabetes mellitus

Table 4 shows the scores for practice of lifestyle modification regarding hypertension and diabetes obtained from the subjects in the groups "exposed" and "unexposed" to the education program.

Overall, the "exposed" group scored significantly higher than the "unexposed" group. Among reported hypertensives, there was no significant difference between the "exposed" and "unexposed" groups in the practice of lifestyle modification for hypertension. Among reported diabetics, however, the scores for practice of lifestyle modifications in diet and physical activity were higher among self-reported diabetics "exposed" to the education program compared to the "unexposed."

\section{DISCUSSION}

Unhealthy nutrition, physical inactivity, excessive use of tobacco, alcohol, and psychosocial stress are major lifestyle issues leading to noncommunicable diseases. Carefully planned community programs are important for prevention. Most strategies for change in chronic disease-related lifestyles have included education of people regarding risk factors. ${ }^{[11]}$ Chronic disease education is not a priority in the developing world unlike in developed countries. ${ }^{[12]}$ Though some communitybased studies have been conducted on the knowledge, attitude, and practice regarding diabetes in India, ${ }^{[13,14]}$ few have focused on the elderly. This study employed a historical cohort design based on the geographic contiguity of the two groups of villages, the similarity in age, and socioeconomic 
and education status of the respondents who were "exposed" and "unexposed" to an education program.

\begin{tabular}{|c|c|c|c|}
\hline \multirow[t]{2}{*}{ Variable } & \multicolumn{3}{|c|}{ Study subjects (\%) } \\
\hline & $\begin{array}{c}\text { Exposed to } \\
\text { education } \\
\text { program }\end{array}$ & $\begin{array}{c}\text { Unexposed } \\
\text { to education } \\
\text { program }\end{array}$ & Total \\
\hline \multicolumn{4}{|l|}{ Age in years ${ }^{*}$} \\
\hline $60-69$ & $32(24.6)$ & 35 (26.9) & 67 (51.5) \\
\hline $70-79$ & $25(9.2)$ & $22(16.9)$ & 47 (36.2) \\
\hline $80 \geq$ & $8(6.2)$ & $8(6.2)$ & $16(12.3)$ \\
\hline Total & $65(50.0)$ & $65(50.0)$ & $130(100.0)$ \\
\hline \multicolumn{4}{|l|}{ Gender } \\
\hline Male & $25(19.2)$ & $25(19.2)$ & $50(38.4)$ \\
\hline Female & $40(30.8)$ & $40(30.8)$ & $80(61.6)$ \\
\hline Total & $65(50.0)$ & $65(50.0)$ & $130(100.0)$ \\
\hline \multicolumn{4}{|l|}{ Education status ${ }^{\star *}$} \\
\hline Illiterate & $33(25.4)$ & 45 (34.6) & $78(60.0)$ \\
\hline Primary school & $15(11.5)$ & $6(4.6)$ & $21(16.2)$ \\
\hline Middle school & $7(5.4)$ & $8(6.2)$ & $15(11.5)$ \\
\hline High school/higher & $10(7.7)$ & $6(4.6)$ & 16 (12.3) \\
\hline Total & $65(50.0)$ & $65(50.0)$ & $130(100.0)$ \\
\hline \multicolumn{4}{|l|}{ Economic status ${ }^{\star \star \star}$} \\
\hline Below poverty line & $41(31.5)$ & $47(36.2)$ & $88(67.7)$ \\
\hline Above poverty line & $24(18.5)$ & $15(11.5)$ & $39(30.0)$ \\
\hline Total & $65(50.0)$ & $62(47.7)^{\dagger}$ & $127(97.7)$ \\
\hline \multicolumn{4}{|c|}{ Self-reported hypertension ${ }^{\star \star \star \star}$} \\
\hline Hypertension & $26(20.0)$ & $9(6.4)$ & $35(26.4)$ \\
\hline No hypertension & $39(30.0)$ & $56(43.6)$ & $95(73.6)$ \\
\hline Total & $65(50.0)$ & $65(50.0)$ & $130(100.0)$ \\
\hline \multicolumn{4}{|c|}{ Self-reported diabetes ${ }^{* * * * *}$} \\
\hline Diabetes mellitus & $23(17.7)$ & $11(8.5)$ & $34(26.2)$ \\
\hline No diabetes & $42(32.3)$ & $54(41.5)$ & $96(73.8)$ \\
\hline Total & $65(50.0)$ & $65(50.0)$ & $130(100.0)$ \\
\hline
\end{tabular}

Knowledge regarding hypertension and diabetes

Studies have reported that basic awareness regarding diabetes is $49.9 \%$ (rural, population of $15-75$ years) and $75.5 \%$ (rural and urban, population of $>20$ years) that increases with age. ${ }^{[13,14]}$ Promoting awareness among the elderly is a means of improving the general level of awareness regarding diabetes, reports one study. ${ }^{[15]}$

Knowledge regarding most aspects of hypertension and diabetes was significantly higher in the population "exposed" to the education program in our study. This finding suggests that education regarding hypertension and diabetes is a useful tool to improve knowledge levels among patients suffering from these diseases, as has been found in other studies. ${ }^{[16,17]}$ However, the overall knowledge scores were less than $50 \%$ of the maximum attainable score even in the "exposed" group. Western studies state that the dose of intervention or scale of exposure to an intervention such as health education has a greater effect on the community. ${ }^{[11]}$ This suggests that even if educational efforts appear to have an effect on the study population, in order to be useful they need to be continuous and sustained. The instrument used to assess knowledge and practice required the respondent to cite every aspect of knowledge/practice to attain the maximum score. This manner of assessment could also have resulted in low absolute scores.

In the Chennai-based Chennai Urban Rural Epidemiology Study (CURES) study, the knowledge among diabetics regarding the risk factors and complications was found

\begin{tabular}{|c|c|c|c|}
\hline \multirow[t]{2}{*}{ A. Among entire study group } & \multirow{2}{*}{$\begin{array}{l}\text { Maximum } \\
\text { attainable score }\end{array}$} & \multicolumn{2}{|c|}{ Mean score $\left(\mathrm{SD}^{\dagger}\right)$} \\
\hline & & "Exposed" group $(n=65)$ & “Unexposed" group $(n=65)$ \\
\hline Knowledge re: Hypertension $(n=130)$ & 34 & $11.17(5.84)$ & $4.97(3.98)^{\star}$ \\
\hline Knowledge re: Diabetes mellitus $(n=130)$ & 41 & $14.85(8.73)$ & $6.57(5.97)^{*}$ \\
\hline \multirow[t]{2}{*}{ B. Among reported hypertensives and diabetics } & Maximum & \multicolumn{2}{|c|}{ Mean score (SD) } \\
\hline & attainable score & “Exposed” group & “Unexposed" group \\
\hline Knowledge re: hypertension (reported hypertensives) $(n=35)$ & 34 & $13.54(4.78)(n=26)$ & $8.67(3.04)^{*}(n=9)$ \\
\hline Knowledge re: diabetes (reported diabetics) $(n=34)$ & 41 & $18.87(8.18)(n=23)$ & $9.64(6.68)^{*}(n=11)$ \\
\hline
\end{tabular}

${ }^{*} P<0.01$, unpaired $t$-test, ${ }^{\mathrm{S}} \mathrm{SD}$ : Standard deviation

Table 4: Practice of lifestyle modifications for hypertension and diabetes mellitus in the study group

\begin{tabular}{|c|c|c|c|}
\hline \multirow[t]{2}{*}{ A. Among the entire study group } & \multirow{2}{*}{$\begin{array}{l}\text { Maximum } \\
\text { attainable score }\end{array}$} & \multicolumn{2}{|c|}{ Mean score (SD') } \\
\hline & & “Exposed” group $(n=65)$ & “Unexposed” group $(n=65)$ \\
\hline Practice re: hypertension $(n=130)$ & 7 & $1.35(1.82)$ & $0.40(1.06)^{*}$ \\
\hline Practice re: diabetes mellitus $(n=130)$ & 8 & $1.49(2.26)$ & $0.34(0.99)^{*}$ \\
\hline \multirow[t]{2}{*}{ B. Among reported hypertensives and diabetics } & Maximum & \multicolumn{2}{|c|}{ Mean score (SD) } \\
\hline & attainable score & "Exposed” group & “Unexposed” group \\
\hline Practice re: Hypertension (reported hypertensives) ( $n=35)$ & 7 & $\begin{array}{c}2.62(2.04) \\
(n=26)\end{array}$ & $\begin{array}{c}1.67(1.12)^{\star *} \\
(n=9)\end{array}$ \\
\hline Practice re: diabetes (reported diabetics) $(n=34)$ & 8 & $\begin{array}{c}3.65(2.27) \\
(n=23)\end{array}$ & $\begin{array}{c}1.18(1.40)^{\star} \\
(n=11)\end{array}$ \\
\hline
\end{tabular}

" $P<0.01,{ }^{* *} P>0.05$, unpaired $t$-test,, SD: Standard deviation 
to be low and was attributed to patients not being educated adequately regarding the disease. ${ }^{[13]}$ Hence, it is not enough to assume that persons with the reported disease know about the disease. In our study, the levels of knowledge even among reported diabetics and hypertensives were lower among those "unexposed" to the education program.

\section{Practice regarding hypertension and diabetes}

Studies have demonstrated the usefulness of risk reduction strategies in the prevention of chronic disease. ${ }^{[11]}$ Educational intervention in the general population emphasizing physical activity and dietary changes have successfully reduced systolic and diastolic pressures in prediabetic adults in rural Tamil Nadu, India. ${ }^{[18]}$ In a Japanese study, the practice of lifestyle modification among the elderly was found to decrease the need for long-term care and also the cost of care. ${ }^{[19]}$

Practice of dietary and physical activity modification to prevent or manage hypertension and diabetes was significantly higher in the group "exposed" to the education program. The difference is less among those with reported disease, as would be expected, considering that the management of the disease when known would include advice on lifestyle change. However, as with the knowledge scores, the overall practice scores were less than $50 \%$ of the maximum attainable scores in both the groups, indicating that more is required to be done.

In conclusion, we found that knowledge regarding hypertension and diabetes is higher among the elderly in villages "exposed" to the educational program. Practice of lifestyle modification (diet, physical activity) is also higher among elderly persons following exposure to the education program. The absolute scores for knowledge and practice were less than $50 \%$ of the maximum attainable score even among the group exposed to the program, indicating a need for more intense and sustained educational efforts. Programs such as introducing a lifestyle intervention booklet may be useful in further reinforcement and improvement of the levels of control of hypertension and diabetes. ${ }^{[20]}$

One limitation of the study is that the baseline scores for knowledge and practice in the two groups before the educational program were not available, precluding a definitive conclusion regarding the usefulness of the educational program. Since the villages were geographically contiguous and the groups appeared to be similar with respect to basic demographic characteristics, the difference in scores might have been due to exposure to the program.

\section{CONCLUSION}

In conclusion, regular health education sessions by physicians, nurses, and community health workers for the elderly are a useful strategy in improving the knowledge and practice for preventing and managing chronic disease, especially in rural areas. This model of prevention in the elderly as demonstrated in this paper can be considered for adaptation by other organizations in similar settings working toward chronic disease prevention.

\section{Acknowledgements}

The authors of the paper acknowledge the assistance received from St. John's Medical College in providing the basic infrastructure for the study. The community health workers attached to the Mugalur Community Health Training Centre of St. John's Medical College were of great help in data collection and identification of the study population. There was no conflict of interest. The study was not supported by any grant, and was conducted as a part of the routine work of the Department of Community Health, St. John's Medical College.

Financial support and sponsorship

Nil.

Conflicts of interest

There are no conflicts of interest.

\section{REFERENCES}

1. Srinath Reddy K, Shah B, Varghese C, Ramadoss A. Responding to the threat of chronic diseases in India. Lancet 2005;366:1744-9.

2. Joshi R, Cardona M, lyengar S, Sukumar A, Raju CR, Raju KR, et al. Chronic diseases now a leading cause of death in rural India--mortality data from the Andhra Pradesh Rural Health Initiative. Int J Epidemiol 2006;35:1522-9.

3. Narula AS. Chronic kidney disease: The looming threat. MJAFI 2008;64:2-3.

4. Ramachandran A, Snehalatha C, Shyamala P, Vijay V, Viswanathan M. High prevalence of NIDDM and IGT in an elderly south Indian population with low rates of obesity. Diabetes Care 1994; $17: 1190-2$.

5. Gupta R. Trends in hypertension epidemiology in India. J Hum Hypertens 2004;18:73-8.

6. Census of India, 2011. Available from http://www.censusindia. gov.in/vital_statistics/SRS_Report/9Chap\%202\%20-\%202011. pdf [Last accessed on 2015 Nov 11].

7. Ashish B. Demographic Transition. Available from: http://www. india-seminar.com/2000/488/488\%20bose.htm. [Last accessed on 2011 Feb 6].

8. Kalavathy MC, Thankappan KR, Sarma PS, Vasan RS. Prevalence, awareness, treatment and control of hypertension in an elderly community-based sample in Kerala, India. Natl Med J India 2000; 13:9-15.

9. Epping-Jordan JE, Galea G, Tukuitonga C, Beaglehole R. Preventing chronic diseases: Taking stepwise action. Lancet 2005;366:1667-71.

10. World Health Organization. Prevention of Cardiovascular Disease, Guidelines for assessment and management of Cardiovascular 
risk. 2007. Available from: http://www.who.int/cardiovascular diseases/guidelines/full\%20text.pdf. [Last accessed on 2011 Feb 4].

11. Nissisnen A, Berrios X, Puska P. Community-based noncommunicable disease interventions: Lessons from developed countries for developing ones. Bull World Health Organ 2001;79:963-70.

12. Kensing C, Boucher J, Cypress M, Weinger K, Mulcahy K, Barta P, et al. National standards for diabetes self management. Diabetes Care 2002;25:140-7.

13. Mohan D, Raj D, Shanthirani CS, Datta M, Unwin NC, Kapur A, et al. Awareness and knowledge of diabetes in Chennai- The Chennai urban rural epidemiology study (CURES-9). J Assoc Physicians India 2005;53:283-7.

14. Rani PK, Raman R, Subramani S, Perumal G, Kumaramanickavel G, Sharma T. Knowledge of diabetes and diabetic retinopathy among rural populations in India, and the influence of knowledge of diabetic retinopathy on attitude and practice. Rural Remote Health 2008;8:838.
15. Sabri AA, Qayyum MA, Saigol NU, Zafar K, Aslam F. Comparing knowledge of diabetes mellitus among rural and urban diabetics. Mcgill J Med 2007;10:87-9.

16. Babaee Beigi MA, Zibaeenezhad MJ, Aghasadeghi K, Jokar A, Shekarforoush S, Khazraei $\mathrm{H}$. The effect of educational programs on hypertension management. Int Cardiovasc Res J 2014;8:94-8.

17. Roopa KS, Devi GR. Impact of intervention programme on knowledge, attitude, practices in the management of hypertension among elderly. Stud Home Com Sci 2014;8:11-6.

18. Kamioka H, Ohsiro H, Mutoh $\mathrm{Y}$, Honda T, Okada S, Takahashi M, et al. Effects of Long term comprehensive health education on the elderly in a Japanese village: Unnan cohort study. Int J Sports Health Sci 2008;6:60-5.

19. Balagopal P, Kamalamma N, Patel TG, Misra R. A communitybased diabetes prevention and management education program in a rural village in India. Diabetes Care 2008;31:1097-104.

20. Wehedy AA, Elhameed SH, El-Hameed DA. Effect of lifestyle intervention program on controlling hypertension among older adults. Journal of Education and Practice 2014;5:61-71. 